\section{Estimating gestational age and its relation to the anthropometric status of newborns: a study comparing the Capurro and ultrasound methods with last menstrual period}

\author{
Estimativa da idade gestacional e sua \\ relação com o estado antropométrico em \\ recém-nascidos: uma comparação dos \\ métodos Capurro e ultrassonográfico com a \\ data da última menstruação
}

\begin{abstract}
Objectives: to assess the accuracy of the Capurro somatic and ultrasound methods, taking date of last menstruation as a reference point, for evaluating gestational age and anthropometric classification of term newborns.

Methods: a prevalence study was carried out involving 309 pregnant women and their term newborns, 92 of whom were small for gestational age and 217 appropriate sized for gestational age, at two public maternity hospitals in the Brazilian city of Salvador. The evaluation of the differences between the median gestational age according to the two methods was carried out using the non-parametric "Wilcoxon Signed-Rank Test." The accuracy of the methods for evaluating gestational age for the small for gestational age newborns was estimated by calculating the sensitivity, specificity, positive predictive value, negative predictive value and ROC (Receiver Operating Characteristic) curve.

Results: compared to ultrasound, the Capurro method overestimated the gestational age in newborns of less than 39 weeks and underestimated it in older newborns. Ultrasound underestimated gestational age in newborns with more than 37 weeks.

Conclusions: ultrasound was found to have greater sensitivity for prediction of small for age newborns (96.6\%), while the Capurro method presented greater specificity (75.5\%). The highest accuracy was obtained using ultrasound in the $41^{\text {st }}$ gestational week $(R O C=77.0 \%)$.
\end{abstract}

Key words Gestational age, Infant, Small for gestational age, Sensitivity and specificity
Maria de Fátima Pussick Nunes 1 Sandra Maria Conceição Pinheiro 2 Fabíola Eloy da Rocha Medrado 3 Ana Marlúcia Oliveira Assis 4

${ }^{1}$ Instituto de Saúde Coletiva. Universidade Federal da Bahia. Rua Padre Feijó, 29, Canela. Salvador, BA, Brasil. CEP: 40110-170. E-mail:mfpnunes@cox.net

2 Centro de Ciências Exatas e Tecnológicas. Universidade Federal do Recôncavo da Bahia. Cruz das Almas, BA, Brasil.

3 Instituto de Perinatologia da Bahia. Salvador, BA, Brasil.

4 Escola de Nutrição. Universidade Federal da Bahia. Salvador, BA, Brasil.

\section{Resumo}

Objetivos: avaliar a acurácia dos métodos físico de Capurro e da ultrassonografia (USG), tomando como referência o método da data da última menstruação (DUM), na avaliação da idade gestacional e classificação antropométrica de recém-nascidos (RN) a termo.

Métodos: estudo de prevalência, envolvendo 309 puérperas e seus recém-nascidos a termo, sendo 92 pequenos para idade gestacional (PIG) e 217 adequados para idade gestacional (AIG), de duas maternidades públicas de Salvador. A avaliação das diferenças entre as medianas da idade gestacional segundo os métodos foi realizada utilizando-se o teste não paramétrico "Wilcoxon Signed-Rank Test." A acurácia dos métodos na avaliação da idade gestacional para o diagnóstico de RN PIG foi verificada através do cálculo da sensibilidade, especificidade, valor preditivo positivo, valor preditivo negativo e curva ROC (Receiver Operating Characteristic).

Resultados: comparado à ultrassonografia, o método de Capurro superestimou a idade gestacional em recém-natos menores de 39 semanas e substimoua naqueles acima deste patamar. A USG substimou a idade gestacional em recém-nascidos com mais de 37 semanas.

Conclusões: na predição de RN PIG, maior sensibilidade foi observada para a USG $(96,6 \%)$ e maior especificidade para o Capurro $(75,5 \%)$. Melhor acurácia foi observada para a USG na $41^{a}$ semana gestacional $($ ROC $=77,0 \%)$.

Palavras-chave Idade gestacional, Recém-nascido pequeno para a idade gestacional, Sensibilidade e Especificidade 


\section{Introduction}

Gestational age, measured in weeks or full days, is defined as the time that has elapsed since the first day of the last normal menstrual period (LMP). ${ }^{1}$ Along with weight at birth, this measurement is an important indicator of neonatal health. ${ }^{2}$

At present, LMP and ultrasound are the principal methods used to estimate gestational age. ${ }^{3-5}$ In situations where information on the menstrual period are difficult to obtain, such as cases of irregular menstrual cycles, bleeding after conception, and failure to remember, LMP is not a reliable way of establishing gestational age and ultrasound is the most commonly recommended method. ${ }^{2}$

More precise ultrasound measures of gestational age up to the tenth week can be obtained by measuring the length of the fetus from head to buttocks, while, up to the $20^{\text {th }}$ week, measurement of the length of the femur or the biparietal diameter is the most appropriate.2,6-8 However, ultrasound examinations are not always carried out in the first twenty weeks of gestation, especially among women who began to receive prenatal care late in their pregnancy.

In the absence of ultrasound data or LMP, the Capurro somatic method ${ }^{9}$ has been used in clinical practice. Although it is widely used, few studies $10-12$ have evaluated the accuracy of the Capurro somatic method 9 for estimating the gestational age and anthropometric parameters at birth compared with LMP and ultrasound. These studies suggest that the Capurro method under- or overestimates gestational age compared with LMP and ultrasound. Despite these limitations, the Capurro method is still commonly used in maternity hospitals, especially when other methods are not available. The use of this procedure has a direct impact on the accuracy of a diagnosis of the anthropometric status of a newborn and hence on the health conditions at birth.

In view of this, this study aims to evaluate the use of the Capurro somatic method and ultrasound, taking LMP as the point of reference, for the estimation of gestational age and anthropometrical classification of term newborns.

\section{Methods}

A cross-sectional study to validate diagnostic methods was carried out at the Climério de Oliveira public maternity hospital and at the Bahia Institute of Perinatology (IPERBA) in the city of Salvador, Brazil, between June 2005 and October 2006. The sample was made up of term newborns ( $\geq 37$ to $\leq 41$ full weeks of gestation), excluding twins and malformed newborns. Newborns that were large for gestational age (weight $\geq 90^{\text {th }}$ ) were likewise excluded from the sampling procedure.

The accuracy of the ultrasound and Capurro somatic methods for evaluation of gestational age and anthropometric status at birth was tested. The LMP method was taken as the point of reference. Given that the sample was not originally intended for this study and information on gestational age provided by the methods under study was not available for all the pregnant women, it was decided that the power of the sample for evaluating the accuracy of measurement of gestational age by each method should be calculated along with its capacity to classify the anthropometric status of newborns. Thus, for a sample of 195 newborns, for whom information on gestational age provided by LMP and Capurro was available, the following were taken into consideration: the difference between the means for the two procedures of $0.2672(\mathrm{DP}=1.30)$ and the significance of $5 \%$, giving a statistical power $(1-\beta)$ of $94 \%$. For evaluation of the difference between the mean gestational age provided by LMP and ultrasound, considering this difference to be 0.5456 ( $\mathrm{DP}=0.98$ ), with a significance of $5 \%$, and a total of 114 newborns, a statistical power $(1-\beta)$ of $100 \%$ was obtained. The data were collected by duly trained researchers in accordance with the criteria and procedures outlined below.

Weight at birth was obtained from the medical records. The newborns were weighed using the service's normal procedure, which consists of weighing the newborn immediately after birth, unclothed, with the umbilical clamped, using an electronic scale with a capacity of $15 \mathrm{~kg}$, sensitivity calibrated at $5 \mathrm{~g}$ and reset for each weighing.

The gestational age was calculated in full months, according to the recommendation of the World Health Organization (WHO). ${ }^{2}$ Validation of the USG and Capurro methods was carried out, using the LMP as a point of reference, in view of its wide use as a method for evaluating gestational age at health centers. ${ }^{2}$ The information on gestational age was obtained by way of an interview and confirmed in the medical records or directly from the report provided by the pregnant woman, in cases where it did not appear in the medical records.

A gestational calendar was used to calculate the gestational age according to LMP and ultrasound. The LMP method was used with those mothers with a regular menstrual cycle (between 25 and 31 days) and date (day and month) as of the last menstrual period. 2 The following ultrasound examinations 
were included in the study: examinations carried out before the $10^{\text {th }}$ week of gestation whose gestational age had been evaluated by measuring the length from head to buttocks, or those carried out between the $11^{\text {th }}$ and $20^{\text {th }}$ week, where the gestational age had been evaluated by measuring the length of the femur or the biparietal diameter. 2,8

The estimation of gestational age using the Capurro method was carried out by neonatologists according to the standard procedure of the health center and registered in the medical records. When this was not available, it was acquired by a duly trained individual.

The method is based on inspection in the first 12 hours of life of physical signs that are placed on a maturation scale 9,10 taking into consideration the following five characteristics of the newborn: skin texture, shape of the ear, size of the mammary nodule, formation of the nipple, and the folds of the sole of the foot.

The characteristics of the newborns were recorded and weighted; adding a constant $(\mathrm{K}=204)$ to the sum of the various points (n). The resulting figure was divided by 7 (equivalent to the number of days in the week), to obtain the gestational age in full weeks. ${ }^{9}$

In $5 \%$ of the sample, an inter- and intra-observer reliability test for the gestational age variable using the Capurro method was carried by the interviewers, using the intra-class correlation coefficient (ICC). The ICC expressed as "rho" was equal to zero, indicating slight probability of the existence of variation from one observer to another and that the measurements taken contained no bias that would affect the study. 13

Anthropometric evaluation was carried out based on the information on birth weight and gestational age using the curve produced by Williams et al.14 The newborns whose weight fell within the $10^{\text {th }}$ percentile of the curve were classified as small for gestational age (SGA) and those whose weight fell between the $10^{\text {th }}$ and $90^{\text {th }}$ percentile of the curve, were classified as appropriate sized for gestational age (AGA).

Two groups were drawn up for the purposes of statistical analysis: one comprising 195 newborns whose gestational age was estimated using the LMP and Capurro methods and another comprising 114 newborns whose gestational age was ascertained using LMP and ultrasound.

The LMP, ultrasound and Capurro methods were submitted to a normality test to see whether they exhibited a normal distribution, using mean, median and mode, arranged in histograms, by means of the
Kolmogorov-Smirnov test. ${ }^{15}$ Where the variable of interest was non-normal, the median was adopted as the statistical parameter to estimate the duration of gestation. The differences between the median gestational ages were tested using the Wilcoxon SignedRank Test. 16

The receiver operating characteristic curve (ROC curve) ${ }^{13}$ was used to establish the cut-off point with the greatest specificity and sensitivity for the gestational age estimation methods in diagnosis of anthropometric status at birth.

The accuracy of the Capurro and ultrasound methods for diagnosis of anthropometric status at birth (considering newborns whose weight falls below the $10^{\text {th }}$ percentile to be SGA) ${ }^{14}$ was evaluated by calculating the sensitivity, specificity, and positive and negative predictive value. The percentage of agreement and disagreement between the methods was also calculated using the Kappa coefficient. For these tests, alpha was set at $<0.05$ and the SPSS 11.0 (SPSS Inc, Chicago, IL) and Stata 8 statistical software packages were used.

\section{Results}

Of the 710 newborns who met the inclusion criteria, 66 were excluded, 20 because their gestational age could not accurately be determined, 25 because they were discharged early from hospital, making it impossible to obtain data, and 21 because their mothers refused to participate. Likewise, 335 newborns whose gestational age was estimated using only one of the three methods were excluded from the study. The final sample thus comprised 309 newborns, 227 of whom (73.5\%) had an estimate for gestational age using two methods and 82 (26.5\%) an estimate based on all three (Figure 1).

The gestational age of seven newborns whose medical records did not contain this information ( $2.3 \%$ of the total sample) was estimated by the interviewers using the Capurro method. The mean weight of the AGA term newborns was $3239.5 \mathrm{~g} \pm$ $321.7 \mathrm{~g}$ (maximum of $4010.0 \mathrm{~g}$ and minimum of $2435.0 \mathrm{~g}$ ). For the SGA term newborns the mean weight was $2562.5 \pm 259.9 \mathrm{~g}$ (maximum of $3000 \mathrm{~g}$ and minimum of $1610 \mathrm{~g}$ ). A low birth weight was found in $2(0.9 \%)$ of the AGA and $60(65.2 \%)$ of the SGA newborns. It was also observed that most of the mothers interviewed $(47.6 \%)$ were socio-economically less privileged. A significant number of them were adolescents (16.9\%); 44.4\% designated themselves as black and $59.9 \%$ had more than four years of schooling.

Table 1 shows the median gestational ages and 


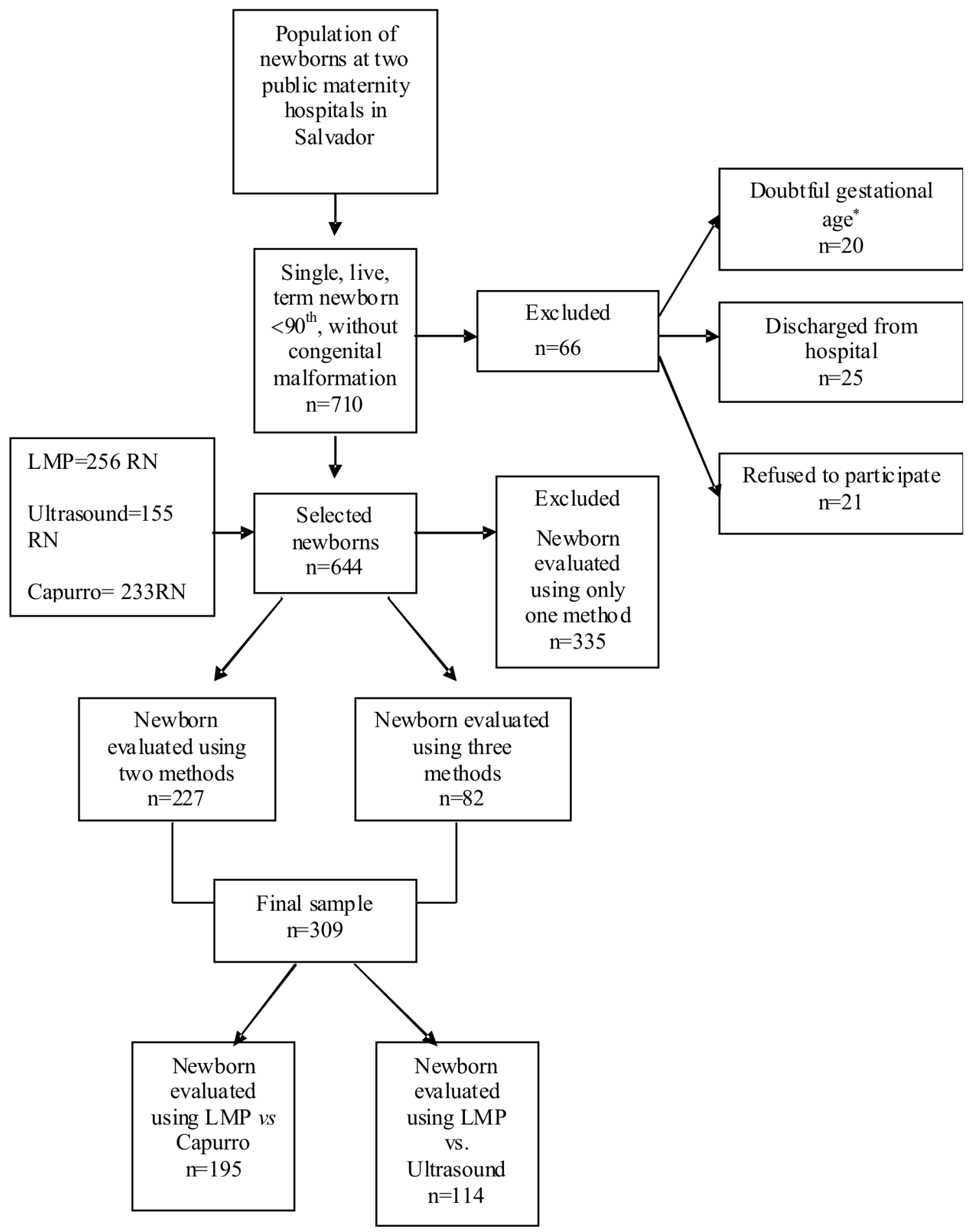

*did not meet the inclusion criteria for any of the three methods for estimating gestational age. 
their respective differences, estimated using a combination of LMP and Capurro or a combination of LMP and ultrasound. Comparison of the median gestational ages estimated using LMP and Capurro revealed that there were differences in the $37^{\text {th }}$ and $38^{\text {th }}$ weeks of gestation, with higher values being returned by the Capurro method. In the $39^{\text {th }}$ week of gestation there were no differences in the medians calculated using the two methods. After the 40th and $41^{\text {st }}$ weeks the opposite trend was observed, with LMP returning higher figures. Overall, the duration of gestation evaluated using LMP (40 GWs) and Capurro (39.5 GWs) was statistically different $(p<0.001)$. It was also noted that this significance was due principally to the differences in the $40^{\text {th }}$ and 41 st gestational weeks, this being the range within which more than half of the newborns included in this study (53.2\%) fell (data not given).

For the LMP and ultrasound methods, it was found that the gestational age estimated using LMP was higher from the $38^{\text {th }}$ week onwards than that calculated on the basis of ultrasound $(p<0.07)$. The differences between the median GAs were statistically significant $(p<0.001)$ for the full length of gestation and, in particular, for the $40^{\text {th }}$ and $41^{\text {st }}$ gestational weeks.

Figures 2 and 3 show the ROC curves used to define the cut-off point (with the higher specificity and sensitivity) for the ultrasound and Capurro methods for assessing the gestational age compared to the LMP for diagnosing newborns as small for gestational age. The bands between the $37^{\text {th }}$ and $41^{\text {st }}$ weeks were tested as cut-off points. Both the ultrasound and the Capurro methods did not show statistical significance between the $37^{\text {th }}$ and $39^{\text {th }}$ week of gestation (data not given). After the $40^{\text {th }}$ week of gestation the areas under the ROC curve reached $64.5 \%$ for ultrasound and $52.4 \%$ for Capurro, (Figure 2), and rose to $77 \%$ and $67.2 \%$ respectively in the 41 st week (Figure 3). Only at this stage, did the area become statistically significant for the ultrasound method USG $(p=0.04)$ and this is considered to be the ideal cut-off point for this method.

\section{Table 1}

Median and difference between medians for gestational age estimated using the LMP method with Capurro and with ultrasound. Salvador, BA, 2005-2006.

\begin{tabular}{|c|c|c|c|c|}
\hline \multicolumn{5}{|c|}{ LMP* vs Capurro $(\mathrm{n}=195)$} \\
\hline GA (weeks) & LMP & Capurro & $p$ & $\begin{array}{l}\text { Difference † (WG) } \\
\text { (LMP versus Capurro) }\end{array}$ \\
\hline 37 & 37,30 & 38,80 & 0,202 & $-1,50$ \\
\hline 38 & 38,30 & 39,10 & 0,001 & $-0,80$ \\
\hline 39 & 39,30 & 39,30 & 0,978 & 0,00 \\
\hline 40 & 40,30 & 40,00 & $<0,001$ & $+0,30$ \\
\hline 41 & 41,20 & 40,00 & $<0,001$ & $+1,20$ \\
\hline Total & 40,00 & 39,50 & $<0,001$ & $+0,50$ \\
\hline \multicolumn{5}{|c|}{ LMP* vs USG $(n=114)$} \\
\hline GA (weeks) & LMP & Ultrasound & $p$ & $\begin{array}{c}\text { Difference }{ }^{\dagger} \text { (WG) } \\
\text { (LMP versus Ultrasound) }\end{array}$ \\
\hline 37 & 37,30 & 37,35 & 0,104 & $-0,05$ \\
\hline 38 & 38,30 & 38,25 & 0,073 & $+0,05$ \\
\hline 39 & 39,30 & 39,20 & 0,252 & $+0,10$ \\
\hline 40 & 40,30 & 40,15 & $<0,001$ & $+0,15$ \\
\hline 41 & 41,20 & 41,00 & $<0,001$ & $+0,20$ \\
\hline Total & 40,00 & 39,50 & $<0,001$ & $+0,50$ \\
\hline
\end{tabular}

*reference; +Wilcoxon Signed-Rank Test;16 GA= gestational age; LMP= last menstrual period; SG= week of gestation. 
Receiver operating characteristic curve (ROC curve) testing the accuracy of the Capurro and ultrasound methods for estimation of gestational age in the $40^{\text {th }}$ week, taking the last menstrual period (LMP) method as the point of reference. Salvador, BA, 2005-2006.

ROC Curve

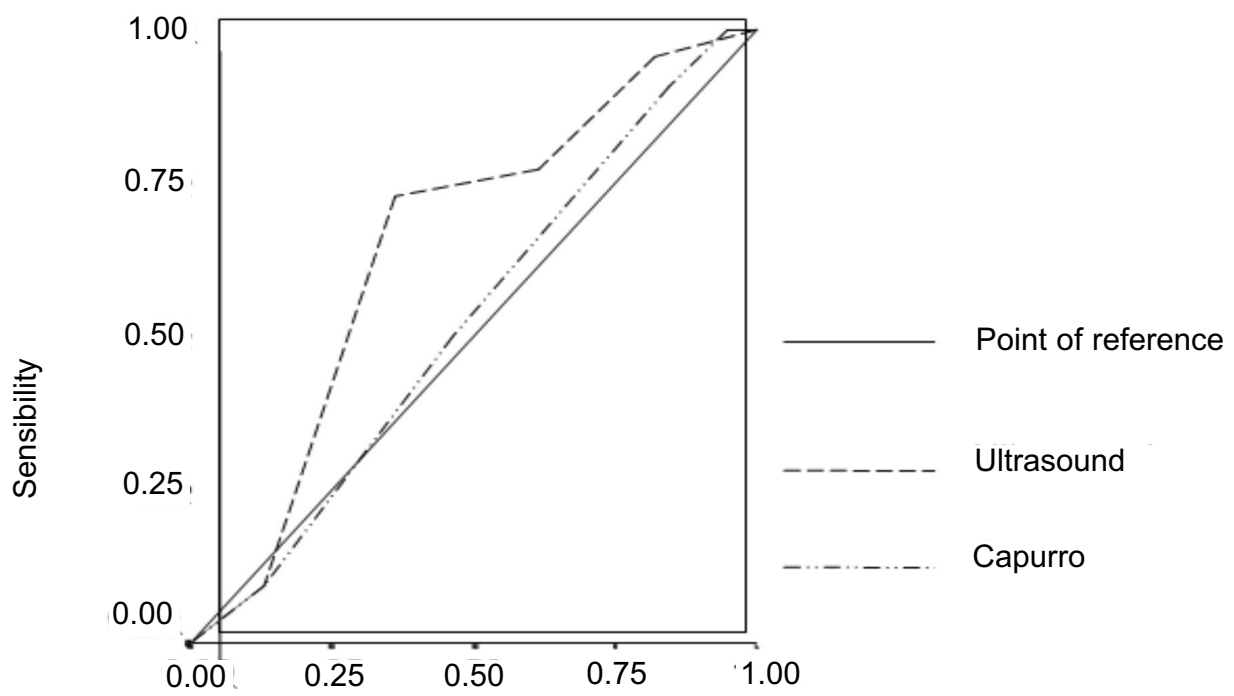

1 - Specificity

\begin{tabular}{lcc}
\hline Parameters & Capurro & Ultrasound \\
\hline Area & 0.524 & 0.645 \\
$p$ value & 0.752 & 0.061 \\
\hline
\end{tabular}


Receiver operating characteristic curve (ROC curve) testing the accuracy of the Capurro and ultrasound methods for estimation of gestational age in the $41^{\text {st }}$ week of gestation, taking the last menstrual period (LMP) as the point of reference. Salvador, BA, 2005-2006.

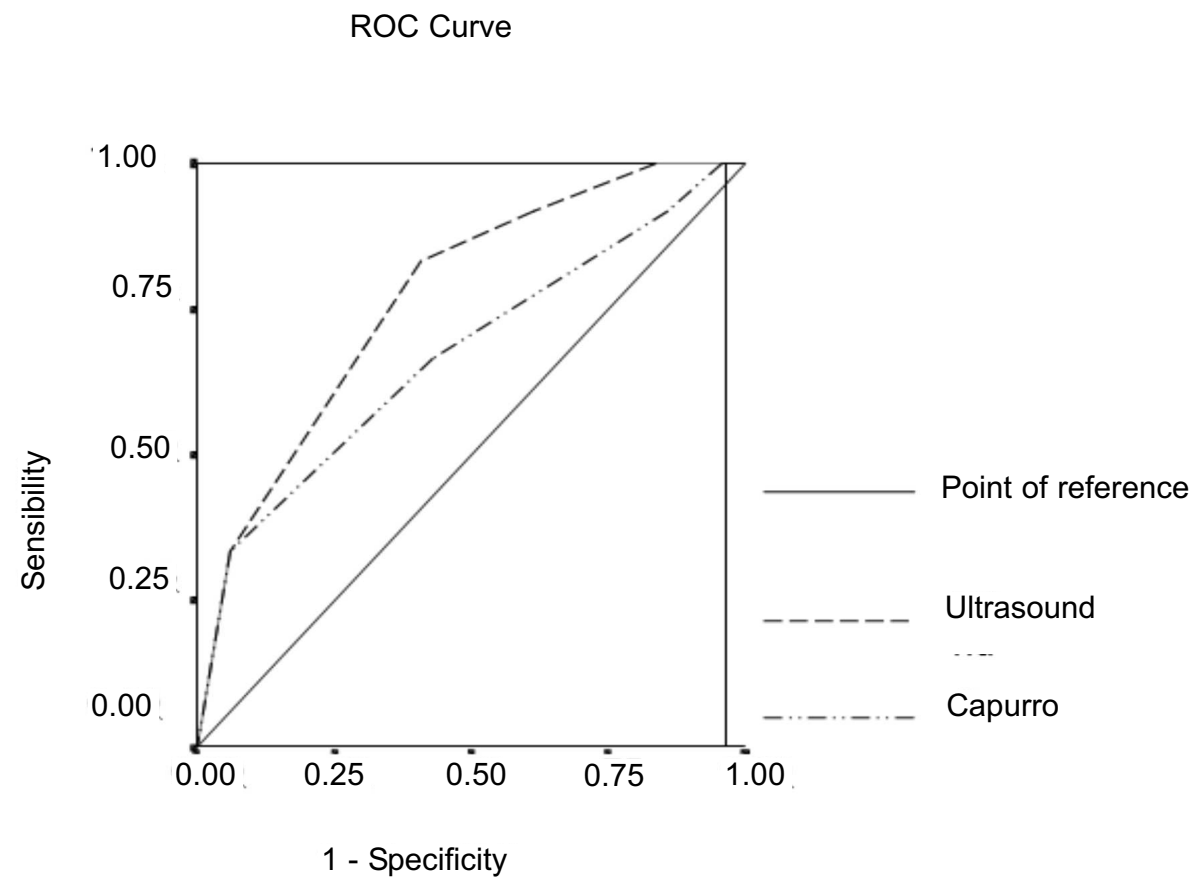

\begin{tabular}{lcc}
\hline Parameters & Capurro & Ultrasound \\
\hline Area & 0.672 & 0.770 \\
$p$ value & 0.067 & 0.040 \\
\hline
\end{tabular}


Table 2 shows the accuracy of the gestational ages estimated according to the different methods for diagnosing SGA newborns, using sensitivity, specificity, positive predictive value and negative predictive value. The gestational age estimated using ultrasound showed a higher sensitivity (96.6\%) CI:(93.2$100)$ for detecting SGA newborns compared with that registered using Capurro (91.3\%) CI: (87.0$95,6)$. However, the specificity of the Capurro method (75.5\%) CI:(68.9-82.1) was higher compared to the ultrasound method $(64.1 \%)$ CI:(55.1-73.1). The positive predictive value was higher when the Capurro method was used $(97.2 \%)$ CI:(94.7-99.7). By contrast, ultrasound revealed a proportion of $96.1 \% \mathrm{CI}:(92.5-99.7)$ of true SGA (negative predictive value).

The percentage of agreement or disagreement of the LMP compared with the combinations of Capurro and LMP and ultrasound and LMP in identifying SGA newborns was also evaluated. The kappa coefficient was high both for LMP and ultrasound (Kappa $=0.87$ ) and for LMP and Capurro $($ Kappa $=0.86)$. Overall, a good agreement $(\mathrm{K}>0.8)$ was found between ultrasound, the Capurro method and LMP; in other words, the proportion of occasions on which the methods for diagnosis of SGA agreed was high.

Table 2

Accuracy of the ultrasound and Capurro methods compared with the last menstrual period (LMP) in determining gestational age for diagnosis of SGA newborns. Salvador, BA, 2005-2006.

\begin{tabular}{lcccc}
\hline Indicators & $\begin{array}{c}\text { LMP* vs USG } \\
(\mathrm{n}=113)\end{array}$ & Cl95\% & $\begin{array}{c}\text { LMP* vs Capurro } \\
(\mathrm{n}=168)\end{array}$ & CI95\% \\
\hline Sensitivity & 96.6 & $93.2-100$ & 91.3 & $87.0-95.6$ \\
Specificity & 64.1 & $55.1-73.1$ & 75.5 & $68.9-82.1$ \\
PPV & 83.9 & $77.0-90.8$ & 97.2 & $94.7-99.7$ \\
NPV & 96.1 & $92.5-99.7$ & 80.0 & $73.8-86.2$ \\
$\%$ agreement** & 86.7 & - & 86.3 & - \\
\% disagreement & 13.3 & - & 13.7 & - \\
Kappa Index ${ }^{\dagger}$ & 0.87 & - & 0.86 &
\end{tabular}

${ }^{*}$ Reference; ${ }^{*}$ Agreement considered to be excellent (Kappa>0.8); PPV= positive predictive value; NPV= negative predictive value; ${ }^{\text {FFleiss, } 1973 .}$

\section{Discussion}

This study found that, compared to LMP, the Capurro method overestimated the gestational age in newborns of less than 39 weeks and overestimated it in those with a higher gestational age. Ultrasound underestimated the gestational age of newborns with more than 37 weeks. Ultrasound was found to have greater sensitivity in the prediction of SGA newborns and the Capurro method greater specificity. The best cut-off point for ultrasound was found to be the $41^{\text {st }}$ week of gestation.

Comparison of the median gestational ages estimated using the Capurro method, taking the LMP method as the point of reference revealed that the former overestimated the gestational age in newborns with less than 39 weeks of gestation and underestimated it in newborns with more than 39 weeks. This difference between the medians became significant in the $40^{\text {th }}$ and 41 st gestational week, the interval into which more than half $(53.2 \%)$ of the births covered by the study fell (data not given). This distortion in the measurement of gestational age increases the chance of incorrect anthropometric classification of newborns. Depending on the weight of the newborn, underestimation of gestational age may lead to SGA newborns being wrongly classified as AGA, thereby impeding the adoption of procedures important for the health of these children. The opposite situation leads to unnecessary costs for health services.

The results found in this study are for term newborns alone and the scope for comparison is thus limited. However, they are broadly in accordance with the findings of Panvini et al.,11 who also showed that the Capurro method tends to underestimate the gestational age of newborns with more than 39 weeks of gestation and to overestimate it for 
newborns with fewer than 39 weeks. The poor accuracy of the Capurro method in estimating gestational age, compared to the LMP method has also been reported by other researchers.10-12 According to Gladys et al. 12 this method tends to underestimate gestational age in preterm newborns and to overestimate it in post-term newborns, when compared with the age calculated using LMP and ultrasound.

In the present study a similar tendency to underestimate gestational age was found for the ultrasound method, taking LMP as the point of reference, in newborns with a gestational age of over 39 weeks. Some studies that have compared these two methods for estimating gestational age have found a similar tendency for ultrasound to underestimate gestational age. 6,7,17 According to Taipale \& Hiilesmaa 6 , even when carried out before the $20^{\text {th }}$ week of gestation, ultrasound registers lower gestational ages than the LMP method, thereby leading to an increase in the estimate for preterm births. 17 In the present study, however, the lower percentage of mothers undergoing ultrasound before the $20^{\text {th }}$ week restricted the size of the sample for this group, which may have affected the robustness of the results. However, recent studies ${ }^{3-5}$ also suggest discrepancies in gestational age as estimated using these two methods and present alternative data analysis procedures as a way of reducing the number of such discrepancies.

The information given in Figures 2 and 3 shows that, in the 41 st week of gestation, ultrasound has a discriminatory power similar to that of LMP for estimation of gestational age, at which point the area of the ROC curve becomes significant $(77 \% ; p=0.04)$ and comparable to that which would be produced by LMP in a hypothetical situation. In view of this, it can be supposed that the best cut-off point for estimating gestational age using the ultrasound method is the $41^{\text {st }}$ week of gestation.

The data in Table 2 show that the sensitivity of the ultrasound (96.6\%) and Capurro methods compared to LMP can be considered high for diagnosis of SGA in newborns. Analysis of the power of the two methods to discriminate true non-cases (AGA newborns) shows, however, that the Capurro method has greater discriminatory power (with a specificity of $75.5 \%$ ) compared to USG (specificity of $64.1 \%$ ). Complementary analysis shows the Capurro method to perform even better for correctly diagnosing truly SGA newborns (VPP=97.2\%) compared to ultrasound (VPP $=83.9 \%)$; suggesting that Capurro can play a role in reaching a correct diagnosis of SGA in nine out of every ten newborns On the other hand, ultrasound succeeded in producing a correct diagnosis in nine out of ten non-
SGA newborns (VPN=96.1\%); while the Capurro method was successful in eight out of every ten cases $(\mathrm{VPN}=80 \%)$.

The findings of the present study suggest that ultrasound was a better predictor of gestational age and anthropometric conditions at birth compared to the Capurro somatic method. However, if it is to be used by health services, adequate validation measures need to be taken and the ultrasound should be carried out before the $20^{\text {th }}$ week of gestation. ${ }^{2}$ However, a certain proportion of pregnant women still start prenatal care late. According to data gathered by the National Demographics and Health Survey on women and children (PNDS) in 200618 in Brazil, $82.5 \%$ of women begin prenatal care in the first trimester of pregnancy, and this percentage is lower in the North region $(78.5 \%)$ and in the Northeast $(73.9 \%)$. In this study, however, only $24.1 \%$ of the mothers had undergone ultrasound prior to the $20^{\text {th }}$ week of gestation and this restricts the use of this method for evaluating gestational age at obstetrics units and consequently the diagnosis of anthropometric conditions at birth.

The Capurro somatic method, despite having received criticism with regard to its validity for estimating gestational age, 10-12 is often the only option available for post-natal estimation of gestational age and it is recommended that it be used with caution in such situations.

The limitations of the study include the fact that the sample only included term newborns, thereby restricting broader comparison between pre- and post-term births. A second limitation was the use of ultrasound and Capurro test results recorded on medical records filled in by different health professionals, which may have given rise to inter-observer bias. A further limitation was the fact that a considerable percentage of mothers were excluded because the gestational age of their children had been evaluated using only one method, especially when this was ultrasound, thereby restricting the size of the sample. Furthermore, each method is known to have its own inherent limitations, which this study attempted to minimize by adopting inclusion criteria and procedures to ensure external validation.

However, in view of the lack of consensus as to the best method for estimating the standard gestational age and the inherent limitations of each, it is perhaps reasonable to argue that evaluation of the state of health and nutrition at birth should include both parameters that estimate the length of gestation and those that include anthropocentric conditions at birth. This suggestion requires further study. 19 Nevertheless, it is fair to say that the methods 
currently used to estimate gestational age do not cover these two areas and are more accurate in estimating one than the other, thereby giving rise to disparities between the measurement of gestational age and the anthropometric parameters at birth.

\section{Acknowledgments}

We would like to thank the Conselho Nacional de Desenvolvimento Científico e Tecnológico (CNPq),

\section{References}

1. WHO (World Health Organization). Recommended definitions, terminology and format for statistical tables related to the perinatal period and use of a new certificate for cause of perinatal deaths. (Modifications recommended by FIGO as Amended October 14, 1976). Acta Obstet Gynecol Scand. 1977; 56: 247-53.

2. WHO (World Health Organization). Physical status: the use and interpretation of anthropometry. Geneva; 1995. p. 121 60. Tech Rep Ser. 854.

3. Dietz PM, England LJ, Callaghan WM, Pearl M, Wier ML, Kharrazi M. A comparison of LMP-based and ultrasoundbased estimates of gestational age using linked California live birth and prenatal screening records. Paediatr Perinatal Epidemiol. 2007; 21 (Suppl. 2): 62-71.

4. Qin C, Dietz PM, England LJ, Martin JA, Callaghan WM. Effects of different data editing methods on trends in racespecific preterm delivery rates, United States, 1990-2002. Paediatr Perinatal Epidemiol. 2007; 21(Suppl. 2): 41-9.

5. Haglund B. Birthweight distributions by gestational age: comparison of LMP-based and ultrasound-based estimates of gestational age using data from the Swedish Birth Registry. Paediatr Perinatal Epidemiol. 2007; 21 (Suppl. 2): 72-8.

6. Taipale P, Hiilesmaa V. Predicting delivery date by ultrasound and last menstrual period in early gestation. Obstet Gynecol. 2001; 97: 189-94

7. Savitz DA, Terry JW, Dole N, Thorp JM, Siega-Riz AM, Herring AH. Comparition of pregnancy dating by last menstrual period, ultrasound scanning, and their combination. Am J Obstet Gynecol. 2002; 187: 1660-6.

8. Chervenak FA, Gabbe SG. Ultra-sonografia obstétrica: avaliação do crescimento e da anatomia fetal. In: Gabbe SG, Niebyl JR, Simpson JL, editores. Obstetrícia- Gestações normais e patológicas. 3 ed. Rio de Janeiro: Guanabara Koogan; 1999. p. 209-10.

9. Capurro H, Konichezky S, Fonseca D, Caldeyro-Barcia R. A simplified method for diagnosis of gestational age in the for financial support by way of a study grant; the neonatologist, Dr. Patrícia Mendes, for her training in the use of the Capurro method; the statistician, Carlos Teles, for his help with data analysis; and the directors of the IPERBA and Climério de Oliveira in Salvador, Bahia, Brazil, for greatly facilitating the collection of data.

newborn infant. J Pediatr. 1978: 93: 120-2.

10. Fescina R, Lastra LGL, Navas JP, Bertone AG, Schwarcz RL. Diagnosis of gestational age: evaluation by different methods. Rev Latinoam Perinatol. 1986; 6: 44-50.

11. Panvini J, Beaujón BO, Gutiérrez A, Borrego M, Aray W, Gómez ML, Schuitemaker J. Validity of the Capurro method in the calculation of the gestational age. Bol Hosp Niños JM de los Rios. 1997; 33: 55-9.

12. Gladys HP, Omar A, Guerrero PB. Efecto del calculo de la edad gestacional en la clasificación del recién nacido. An Venez Nutr. 1996; 9: 5-10.

13. Hosmer DW, Lemeshow S. Applied logistic regression. 2 ed. New York: John Willey \& Sons INC; 2000.

14. Williams RL, Creasy RK, Cunnigham GC, Hawes WE, Norris FD, Tashiro, M. Fetal growth and perinatal viability in California. Obstet Gynecol. 1982; 59: 624-32.

15. Lindgren BW, McElrath GW. Introdução à estatística. 3 ed. Rio de Janeiro: SA; 1972.

16. Soares JF, Siqueira AL. Introdução à estatística médica. Belo Horizonte: Departamento de Estatística/ UFMG; 2001.

17. Yang H, Kramer MS, Platt RW, Blondel B, Bréart G, Morin I, Wilkins R, Usher R. How does early ultrasound scan estimation of gestational age lead to higher rates of preterm birth? Am J Obstet Gynecol. 2002; 186: 433-7.

18. Brasil. Ministério da saúde. Centro brasileiro de análise e planejamento. Pesquisa Nacional sobre Demografia e Saúde da criança e da mulher. PNDS 2006. Brasília, DF; 2008. [Acesso em 7 set 2009]. Disponível em: http://bvsms.saude.gov.br/bvs/pnds/img/relatorio_final_ pnds2006.pdf

19. Wingate MS, Alexander GR, Buekens P, Vahratian A. Comparison of gestational age classifications: date of last menstrual period vs. clinical estimate. Ann Epidemiol. 2007; $17: 425-30$
Recebido em 6 de janeiro de 2010

Versão final apresentada em 14 de dezembro de 2010

Aprovado em 18 de janeiro de 2011 